\title{
La oposición eficaz. Análisis basado en el proceso monitorio del Código General del Proceso*
}

\author{
Daniela Corchuelo Uribe ${ }^{* *}$ \\ 1 Mónica Alejandra León Gil.**
}

... El Derecho es justicia [...] El Derecho es el arte de lo bueno y equitativo.

D. I.I.I

Resumen: El proceso monitorio es una herramienta novedosa en Colombia. Se erige como la forma más eficaz de solucionar controversias cuando los acree-

Ponencia del Equipo ganador del Concurso Internacional de semilleros del Instituto Colombiano de Derecho Procesal 2015. Dirigido por Daniela Corchuelo Uribe y Mónica Alejandra León Gil, integrado por Daniela Amaya Castro, Laura Andrea Anaya Quintero, Luisa María Brito Nieto, Juan Andrés Chávez Polanco, Shaid de Jesús Gómez Dau, Diego Nicolás Mondragón Ariza, Sergio Felipe Salamanca Borrero, Luis Alejandro Roa Caballero, Diego Fernando Rojas Vásquez y Laura Velandia Ortegón, estudiantes de la Universidad Externado de Colombia, Bogotá, Colombia. Contacto: daniamayac@hotmail.com, laura. aq05@hotmail.com, lbritonieto@outlook.com, jacpolanco@hotmail.com, sayo9225@hotmail. com, dnmondragon.ariza@outlook.com, felipe-sergioro93@hotmail.com, larc4565@gmail. com, diegorojasvasquez@outlook.com, laura.velandiao2@est.uexternado.edu.co

Fecha de recepción: 26 de octubre de 20 I 5. Fecha de aceptación: 2 I de marzo de 20 i 6.

Para citar el artículo: D. Corchuelo Uribe; M. A.; León Gil et al., "La oposición eficaz. Análisis basado en el proceso monitorio del Código General del Proceso", Revista de Derecho Privado, Universidad Externado de Colombia, n. ${ }^{\circ}$ 30, enero-junio de 20 16, 339-369. DOI: http://dx.doi. org/I o. I 860 I/o I $234366 . n 30$. I I

** Abogada de la Universidad Externado de Colombia, Bogotá, Colombia. Auxiliar de investigación del Departamento de Derecho Procesal de la Universidad Externado de Colombia, Bogotá, Colombia. Candidata a obtener el título de Master in International Disputes Settlement de la Universidad de Ginebra y Graduate Institute of International and Development Studies. Contacto: daniela.corchuelo@uexternado.edu.co y danielacorchuelo@gmail.com

*** Abogada de la Universidad Externado de Colombia, Bogotá, Colombia. Auxiliar de investigación y docente del Departamento de Derecho Procesal de la Universidad Externado de Colom- 
dores no disponen de título ejecutivo, y busca garantizar la tutela efectiva del crédito, procurando la celeridad y eficiencia de la administración de justicia. Su característica esencial es la inversión del contradictorio. Allí, el deudor manifiesta las razones por las que considera no deber, por medio de una oposición, que según el Código debe ser fundada, sin que determine su alcance. Este estudio busca dotar de contenido la oposición con el fin de ofrecer herramientas al intérprete, para que decida atendiendo a los principios del derecho procesal.

Palabras Clave: proceso monitorio, oposición fundada, oposición razonada, valoración preliminar, valoración posterior, excepciones previas, derecho de defensa, celeridad, lealtad procesal, eficiencia.

\section{Effective Opposition: An Analysis based on the Procedure for the Order for Payment under General Procedural Law}

Aвstract: The procedure for the order for payment is a new tool in Colombian legislation that stands as the most effective way of solving certain disputes arising with creditors when they lack an enforceable title. Thus, the legal system seeks to ensure effective protection of credit by ensuring a speedy and efficient administration of justice. The essential feature of this procedural institution is the overcoming of the burden of proof. Here, the debtor (the defendant) states the reasons why it considers it has no duty. However, the legislature merely refers to an empty concept as it does not determine the scope of the duty or its foundation. This study seeks provide the interpreters of the law with tools to allow them to understand the opposition according to the principles of Procedural Law.

Keywords: Procedure for the Order for Payment, founded opposition, reasoned opposition, preliminary assessment, subsequent assessment, preliminary objections, right to defense, celerity, procedural loyalty, efficiency.

Sumario: Introducción. I. Antecedentes jurídicos del proceso monitorio. II. Nociones generales y su regulación en el Código General del Proceso. A. Definición lingüístico-jurídica y su finalidad. B. Naturaleza jurídica. C. Clasificación. D. Procedencia. E. Figuras procesales prohibidas en el proceso monitorio. F. Procedimiento. III. Efectos de la oposición en el Código General del Proceso. A. El efecto de impedir la ejecución. B. Multa. Iv. Exigencias de la oposición en

bia, Bogotá, Colombia. Candidata a magíster en Derecho con énfasis en Derecho Procesal por la Universidad Externado de Colombia. Contacto: monica.leon@uexternado.edu.co y monicaalejandra.leon@hotmail.com 
otros países. A. Uruguay. B. España. C. Costa Rica. D. Conclusiones generales respecto al contenido de la oposición en otros países. v. Contenido y alcance de las exigencias de la oposición en otras figuras del Código General del Proceso. A. Juramento estimatorio. B. Oposición a la entrega de bienes. C. Oposición en el proceso de deslinde y amojonamiento. D. Oposición a la exhibición de documentos. E. Conclusión general respecto al contenido de la oposición en otras figuras del Código General del Proceso. vi. Relevancia del alcance de la oposición: defensa y eficiencia. A. Valor preliminar. B. Valoración posterior. viI. En busca de un criterio de valoración adecuado. A. Sobre la valoración preliminar. B. Sobre la valoración posterior. viII. De las excepciones como consecuencia de un criterio apropiado para la oposición. A. Excepciones de mérito. B. Excepciones previas. Conclusiones.

\section{Introducción}

La justicia es el principal valor y fin de toda sociedad, y el derecho es concebido, entre otros medios, para garantizarla. Sin embargo, varias de las estructuras y procedimientos que se han concebido para tutelar los derechos de los coasociados resultan, en ocasiones, exiguos para el logro de dicho cometido. Por tal razón, ha trascendido la idea de que la justicia tardía es injusticia y, por ende, para materializarla no es suficiente con "dar a cada quien lo suyo", sino que es menester hacerlo en la forma y tiempo debidos.

La congestión del aparato jurisdiccional, que se traduce en demoras ineludibles, constituye un obstáculo para la justicia efectiva, por lo que se tornó necesaria la creación de una institución procesal que permita prescindir de formalidades superfluas y con ello garantizar la eficiencia y celeridad del proceso. Bajo esta óptica resulta ideada la estructura del proceso monitorio, que es el modelo más adecuado para obtener una actuación expedita de la jurisdicción en aras de la tutela del derecho de crédito. Esta celeridad se logra concediendo al deudor la posibilidad de iniciar el contradictorio únicamente mediante su oposición que, en el caso colombiano, debe ser razonada y fundada.

No obstante las bondades del proceso monitorio, la caracterización que hace el Código General del Proceso colombiano (c.g.p.) de la oposición del deudor, como razonada y fundada, genera indeterminación sobre cuál es la oposición eficaz. De ahí que corresponda al operador jurídico el deber de realizar una labor hermenéutica a efectos de determinar la procedencia de la sentencia condenatoria, que tiene lugar cuando no hay oposición eficaz, y la imposición de una multa a la parte vencida. Esa interpretación, necesariamente, deberá asegurar la realización de los principios de lealtad procesal y eficiencia del proceso monitorio, sin que ello implique un menoscabo del derecho de defensa. 


\section{Antecedentes jurídicos del proceso monitorio}

Cuando se habla del origen del proceso monitorio, generalmente se hace alusión al derecho italiano y germánico del medioevo; pese a ello, resulta difícil hallar vestigios de esta institución antes del siglo xIv, en la medida en que existe indeterminación alrededor de las circunstancias de modo, tiempo y lugar en las que tal figura fue concebida. No obstante, es factible encontrar antecedentes disgregados antes de esta fecha que han podido influir en la ideación de una de las principales características del proceso monitorio: la condena ante la inactividad del demandado ${ }^{\mathrm{I}}$.

En primer lugar, el Edicto de Rotario promulgado en el año 643, que fue la primera recolección escrita de las leyes de los lombardos. En este se establece que si el demandado deja el proceso en suspensión durante un lapso mayor a un año, la sanción es la condena. Por otro lado, esta equiparación entre silencio y condena también se evidencia en la Mishneh Torah, que es una compilación sistemática de la ley judía hecha en la década de i r7o, la cual dispone que la renuencia del demandado a prestar juramento da lugar a una condena ${ }^{2}$. Por último, en Roma encontramos el procedimiento del solemnis ordo iudiciarius, entendido como un tipo de proceso común romano-canónico medieval ${ }^{3}$, al ser una reminiscencia tanto de normas procesales de la cognitio extra ordinem como de reglas del proceso canónico.

El solemnis ordo iudiciarius contaba con una fase previa consistente en una solicitud escrita que la parte actora emitía para que se requiriera a la contraparte con el fin de que esta declarara si iba a oponerse, caso en el cual el proceso empezaba con la interposición de una demanda. Es necesario analizar este proceso en el marco evolutivo que supuso el paso del agere per formulas, caracterizado por el impulso procesal de las partes, a la cognitio extra ordinem, en la cual el Estado -en razón de la expansión del territorio romano- no se limitó a emitir la fórmula que otorgaba la acción, sino que tuvo una participación más activa4.

En consecuencia, la notificación al demandado pasó de ser una carga del accionante a un deber del Estado. Es así como aparece la figura de la litis denunciatio $^{5}$ como primer antecedente de la fase previa anteriormente mencionada, el

I Fenoll, J., "Aproximación al origen del procedimiento monitorio", fusticia n. o I, 20 I 3, I I4.

2 Ibíd., I I 5 .

3 España, Ministerio de Justicia, Materiales para una reforma procesal [en línea], Madrid, 362 , disponible en: https://books.google.com.co/books?id=OxN6ZWOU4rkC\&pg=PA36 I \&lpg=$\mathrm{PA}_{3} 6 \mathrm{I} \& \mathrm{dq}=$ solemnis + ordo+iudiciarius + en + roma \& source=bl\&ots=t9-UIZOhHw\&sig=X $4 \mathrm{O}$ JKyilrWGo7f $f_{\text {yFIWTKAf } 2 \text { k } 20 \& h l=e s \& s a=X \& e i=3 x k e V c L L H c G b g w S L} 2$ YGADw\&ved=o CCEQ6AEwAQ\#v=onepage \& $\mathrm{q}=$ =solemnis $\%$ 2 oordo\% 2 oiudiciarius $\%$ 2 oen $\%$ 2 oroma \& $\mathrm{f}=$ false [consultado el 3 de abril de 2015].

4 Fenoll, ob. cit., i i 8 s.

5 Posteriormente reemplazado por el proceso del libelo. 
cual consiste en la elaboración de un escrito por el demandante en el que, sin mayor formalidad, expresaba sus peticiones. Posteriormente, el juez notificaba al demandado y este tenía cierto plazo para comparecer, pues si no lo hacía se tenía como un rebelde del ordenamiento y se le sancionaba con la emisión de un edictum peremptorium, en virtud del cual el proceso podía ser fallado en su contra sin un análisis de fondo de la demanda ${ }^{6}$.

Si bien las acciones mencionadas no corresponden propiamente al proceso monitorio, se encontraron en ellas bases estructurales sólidas que coadyuvaron a la posterior constitución del mismo en Italia con el mandatum de solvendo cum clausula iustificativa, siendo este no un proceso novedoso, sino la transformación de la fase monitoria de un proceso declarativo (como era en el derecho romano) a un proceso especial con singulares características.

De este modo, con ocasión del desarrollo comercial, especialmente marítimo, en las ciudades italianas de la baja Edad Media empezaron a presentarse conflictos de carácter económico que hicieron que se tornara necesario el uso de un proceso menos formalista, diferente al ordinario, que permitiera agilizar el tráfico mercantil7. Así, se establece el proceso monitorio de manera pura: el juez expedía un mandatum de solvendo ante la mera afirmación de la parte actora, es decir, no se requería justificación del crédito; pero, a su vez, tenía una cláusula iustificativa que le daba la facultad al deudor de ejercer la oposición ${ }^{8}$. Actualmente es de naturaleza documental y está regulado en los artículos 633 a 656 del codice di procedura civile para los eventos de cobro de sumas de dinero, cosas fungibles o entrega de cosas determinadas.

Con posterioridad, alrededor del siglo xv, el proceso monitorio se propagó al derecho germánico, y, a su vez, se exportó a los demás países europeos en razón de la necesidad de agilidad y seguridad en las transacciones comerciales que cada vez eran más frecuentes y complejas 9 . La adopción del proceso monitorio en Europa tuvo como excepción España, que no lo reguló en las leyes de enjuiciamiento civil de i 855 y I 88 I. Por esto, al estar la legislación hispanoamericana basada en las leyes españolas, no se incluyó este proceso foráneo sino en I989, cuando Uruguay se puso a la vanguardia con el Código General del Proceso.

6 FENOLL, ob. cit., I 20.

7 Andrade, J., Estudio del proceso monitorio y del proceso ejecutivo [en línea], 20I3, disponible en: http://gestionlegalyempresarial.com.co/inicio/index.php/actualidad/ı 66-el-proceso-monitorio [consultado el 5 de abril de 2015].

8 Rivera, R., Del procedimiento por intimación [en línea], 2, disponible en: http://www.google.com/ur 1 ? $\mathrm{sa}=\mathrm{t} \& \mathrm{rct}=\mathrm{j} \& \mathrm{q}=\&$ esrc $=\mathrm{s} \&$ source $=\mathrm{web} \& \mathrm{~cd}=4 \& \mathrm{cad}=\mathrm{rja} \& u a c t=8 \& \mathrm{ved}=\mathrm{oCDEQFjAD} \& \mathrm{url}=\mathrm{htt}$ p \% ${ }_{3} \mathrm{~A} \%_{2} \mathrm{~F} \%{ }_{2} \mathrm{Fwww}_{w}$.colmenaresabogados.com \% 2 Fuserfiles $\%_{2}$ FProceso \% 2520 Monitorio\% $2520 e n \% 2520$ Venezuela \% 25 20rodrigo\% 252 orivera.doc\&ei=lt4pVfz4HviIsQTy6IGYBQ\&usg=AFQjCNE 2 mYPckbSArgbTFSUE- 7 lFoeo $8 \mathrm{qA} \&$ sig $_{2}=\mathrm{j}_{3}$ fw $8 \mathrm{jBh} 8 \mathrm{OZXKVht}-$ yBylg\&bvm=bv.9049 I I 59, d.cWc [consultado 3 de abril de 201 5 ].

9 Andrade, ob. cit. 
En Colombia, el proceso monitorio es incorporado en el nuevo Código General del Proceso en razón de una necesidad social de protección a determinados acreedores $^{\mathrm{IO}}$ que por habitualidad mercantil no tienen la costumbre de dejar constancia por escrito de sus transacciones dinerarias. De este modo, tal proceso se implementa con la finalidad de tutelar el derecho de crédito, lo que conlleva, a su vez, hacer efectivo el derecho fundamental de acceso a la administración de justicia, el cual se traduce no solo en la posibilidad de plantear pretensiones ante la autoridad judicial competente, sino también, entre otros, en la obtención de una resolución sin dilaciones injustificadas. Así, en la medida en que estos acreedores sin título ejecutivo vean puesto en entredicho el amparo de su crédito en virtud de la exigencia de formalidades que muchas veces resultan inocuas, se podría afirmar con certeza que el derecho a poner en funcionamiento el aparato jurisdiccional para la solución de controversias no estaría siendo garantizado por el Estado ${ }^{\mathrm{I}}$.

\section{Nociones generales y su regulación en el Código General del Proceso}

\section{A. Definición lingüístico-jurídica y su finalidad}

Los vocablos ‘monitorio’ y ‘monición', según el Diccionario de la Real Academia Española (DRAE), significan, avisar/amonestar y advertencia dirigida a alguien, respectivamente ${ }^{\mathrm{I} 2}$. Lo anterior da a entender, según Colmenares URIBE, que el proceso monitorio se refiere a un requerimiento de pago que hace el juez al deudor para que cumpla con la obligación a su cargo, bajo la advertencia del riesgo de obtener una sentencia desfavorable que declare su existencia si no paga o justifica su renuencia ${ }^{13}$.

Entonces, se trata de un trámite expedito que les facilita obtener un título ejecutivo a los acreedores de obligaciones dinerarias, contractuales, exigibles, determinadas y de mínima cuantía ${ }^{\mathrm{I}}$, que no constan en uno, sin la necesidad de

Io Las obligaciones de estos acreedores protegidos por el proceso monitorio deben tener características especiales que se exponen con posterioridad.

i i Colombia, Corte Constitucional. Sentencia C-726 del 24 de septiembre de 20i4, M.P.: Martha Victoria Sáchica Méndez, exp. D-ı I I 5.

I 2 Definición tomada de la página web oficial del DrAE: http://lema.rae.es/drae/?val=monitorio. Recuperado: io de abril de 2015 .

i 3 Colmenares, C. A., "El proceso monitorio en el Código General del Proceso", en xxxiII Congreso Colombiano de Derecho Procesal (I2-I4, septiembre, 2oI 2: Cartagena, Colombia). Memorias, Bogotá, Universidad Libre, 2012 , I 48.

I4 Ley I 564 de 2012 (I 2 de julio, Colombia). Por medio de la cual se expide el Código General del Proceso y se dictan otras disposiciones. Diario Oficial. Bogotá, 2012 , n. ${ }^{\circ} 48.489$. Artículo 4I 9. 
acudir a un proceso declarativo verbal y, a su vez, acceder a su ejecución ante la no oposición del demandado ${ }^{15}$.

En otras palabras, la finalidad del proceso monitorio es permitir que con la mera afirmación del acreedor-demandante sobre la existencia de la deuda a su favor, se genere una orden de pago judicial cuando el deudor-demandado no se oponga a ello, sin perjuicio de que, en el caso de existir, se aporten con la demanda uno o varios documentos de los cuales se pueda inferir la obligación que se reclama. Esto, puesto que la afirmación jurada que hace el demandante de la existencia de su crédito se prevé solo para el supuesto en el cual no posea ningún documento o no tenga conocimiento de la existencia de alguno $^{\text {16-17 }}$.

Así pues, la justificación de ser un proceso rápido y sencillo que facilite el acceso a la administración de justicia y permita obtener una solución oportuna con la cual se garantice la tutela judicial efectiva del crédito, la encontramos al observar que el legislador, ante la oposición, consagró su continuación mediante el trámite verbal sumario, el cual sigue siendo de única instancia ${ }^{18}$.

\section{B. Naturaleza jurídica}

El proceso monitorio se encuentra ubicado en el Código General del Proceso dentro de los procesos declarativos especiales como una forma novedosa de tutela privilegiada del crédito $^{19}$. Está caracterizado fundamentalmente: por la creación rápida de un título ejecutivo a favor del acreedor, inaudita pars; por la inversión del contradictorio ${ }^{20}$, y por un trámite verbal sumario ante la oposición razonada del deudor, con la prohibición de determinadas figuras procesales ${ }^{21}$.

\section{Clasificación}

Existen dos criterios para clasificar el proceso monitorio ${ }^{22}$. El primero versa sobre la finalidad o función del título ejecutivo que se origina con el proceso, refiriéndose a la existencia de: i) un proceso monitorio puro que se inicia con la simple afirmación del acreedor de ser titular de un crédito que no consta en do-

I 5 Sentencia C-726 de 20 I4.

I6 Canosa, U., Proceso Monitorio [videograbación], disponible en:_https://www.youtube.com/ watch?v=L-Exel 3 mo8o [consultado el io de abril de 2015]. Publicado el 20 de noviembre de 20 1 2, en seminario "Nuevo Código General del Proceso", 2 y 3 de agosto de 2012, Departamento de Derecho Procesal, Universidad Externado de Colombia.

I 7 Ley I564 de 2012 . Artículo 420, numeral 6.

I8 Ibíd., artículo 42 I, parágrafo.

i9 Canosa, ob. cit.

20 Colmenares, ob. cit., i I 57.

2 I Ley I 564 de 2012 . Artículo 42 I, incisos 4 y 6.

22 Colmenares, ob. cit., I I 5 O-I I 52. 
cumento alguno, y ii) un proceso documental, en el cual se exige que el acreedor, al demandar, aporte un documento del cual se pueda inferir la existencia de una deuda a cargo del demandado 23 .

El segundo se estructura según la cuantía de la pretensión que se reclama. Así, se enuncia la existencia de un proceso monitorio limitado y otro ilimitado, en el cual solo es admisible una reclamación judicial hasta cierto monto o sin importar el mismo, respectivamente ${ }^{24}$.

Según lo anterior, el proceso monitorio en Colombia es, por un lado, documental y, excepcionalmente, puro $^{25}$, cuando se afirme bajo juramento que no se tiene ningún documento que refleje el principio de prueba por escrito que se exige en el documental ${ }^{26} \mathrm{y}$, por el otro, limitado porque solo es admisible acudir a él para la reclamación de obligaciones dinerarias de mínima cuantía.

\section{Procedencia}

El Código General del Proceso en su artículo 4I9 delimita, a través de los siguientes requisitos, los asuntos que pueden ser adelantados por medio de este proceso.

I. Se debe tratar de una obligación dineraria. Hace referencia a "aquellas obligaciones cuya prestación consiste en dar-entregar (transferir) una cantidad de unidades monetarias" 27 de curso legal. De esta forma, la normatividad excluye del campo de aplicación de este proceso aquellas obligaciones en las que el praestare consista en una conducta positiva (bien sea facere o dare, diferente de la entrega de una suma de dinero) o de abstención (non-facere) por parte del deudor.

2. La obligación debe ser de naturaleza contractual. El contrato, verbal o escrito, es la única fuente de la relación, que por su propia voluntad ha sido establecida entre el deudor y el acreedor del posible litigio.

3. La obligación debe ser determinada y exigible. La primera característica se refiere al carácter cierto del monto de unidades monetarias al que está obligado el deudor; la segunda hace alusión a la facultad que tiene el acreedor para exigir el cumplimiento de la obligación, es decir, cuando la obligación es pura y simple o cuando, estando sometida a un plazo o condición, este ya se ha vencido o cumplido $^{28}$.

23 Joan Picó I Junoy, "El proceso monitorio. Una visión española y europea pensando en Colombia”, en XXXIII Congreso Colombiano de Derecho Procesal. (I 2 al I4 de septiembre, 20I 2: Cartagena, Colombia). Memorias, Bogotá, Universidad Libre, 20 I 2, IO25.

24 Ibíd.

25 Colmenares, ob. cit., I I 5 I.

26 Ley I 564 de 2012 . Artículo 420, numeral 6, inciso 2.

27 Hinestrosa, F., Tratado de las obligaciones, $3 \cdot{ }^{a}$ ed., Bogotá, Universidad Externado de Colombia, 2007 .

28 Ibíd. 
4. De mínima cuantía. La suma de todas las pretensiones causadas hasta el momento de la presentación de la demanda (capital e intereses) no puede superar los 40 salarios mínimos legales mensuales vigentes ${ }^{29}$. De este requisito se deduce que el proceso tiene un trámite de única instancia, así como la facultad que tienen demandado y demandante para actuar en él sin abogado ${ }^{3 \circ}$.

5. La suma adeudada no debe depender del cumplimiento de una contraprestación a cargo del acreedor. Se refiere a la excepción de contrato no cumplido, que es la facultad de una de las partes del contrato de abstenerse de cumplir sus obligaciones, cuando estas dependen del cumplimiento de las de la contraparte.

\section{E. Figuras procesales prohibidas en el proceso monitorio}

Siendo la simplificación un rasgo característico del proceso monitorio, el parágrafo del artículo 42 I c.g.p. dispone que "en este proceso no se admitirá intervención de terceros, excepciones previas, reconvención, el emplazamiento del demandado, ni el nombramiento de curador ad litem...". Lo anterior encuentra su justificación en la celeridad y eficiencia ${ }^{3 \mathrm{I}}$ por las que propende este proceso; sin embargo, es necesario poner de presente la tensión existente entre los mencionados principios y otros, como el de la lealtad procesal y el del debido proceso, pues el demandado no tiene mecanismos -ni tan siquiera alternativos- por medio de los cuales pueda manifestar circunstancias procesales que configuren causales de excepciones previas, que en un proceso declarativo normal podrían incluso dar lugar a la terminación del mismo. La situación acá planteada se dilucida a lo largo del presente escrito.

\section{F. Procedimiento}

Sin mayores formalismos procedimentales, el proceso inicia con la demanda interpuesta por el acreedor, en cumplimiento de los requisitos consagrados en el artículo 82 c.g.p. Con el fin de resolver las posibles dificultades técnicas a las que se pueda enfrentar el demandante en el ejercicio de su derecho sin abogado, el Consejo Superior de la Judicatura dispuso formatos para facilitar la actuación del demandante y del demandado en el proceso. No obstante, dichos formatos difícilmente podrán cumplir esta finalidad, pues se requiere un mínimo de cono-

29 Para el año 201 5 el Gobierno decretó que el monto del salario mínimo sería de \$ 644·350.

30 "Se restringe el proceso monitorio a los procesos de mínima cuantía, dejando por fuera los de menor que habían sido incluidos dentro del texto aprobado en segundo debate, por considerarlo adecuado para la implementación de la figura por primera vez en el territorio nacional y en el entendido de que se incrementan las cuantías": Informe de Ponencia para Primer debate al Proyecto de Ley i 59 de 20 i I Senado, ig6 de 20 i I Cámara, Gaceta i i 4.

$3^{\text {I }}$ El concepto de eficiencia se refiere al logro de los fines del proceso en el menor tiempo posible. 
cimientos jurídicos para su diligenciamiento, esto es, entender conceptos como pretensiones, pruebas, fundamentos de derecho, medidas cautelares, entre otros.

Valorados los requisitos y admitida la demanda, el juez requiere al deudor para que en el plazo de io días ejerza su derecho de defensa, bien sea pagando o presentando en la contestación de la demanda los motivos por los cuales se opone a las pretensiones del demandante, total o parcialmente. Además, la norma ordena al deudor que, en el término de traslado, aporte las pruebas que sustenten su oposición, verbigracia los documentos que se encuentren en su poder.

El auto que contiene el requerimiento de pago, tal como lo menciona el Código, no tiene recursos y debe ser notificado personalmente por el acreedor en la forma establecida en el artículo 29I dentro del término de un año para que se interrumpa la prescripción, se haga inoperante la caducidad y se constituya en mora al deudor. La notificación personal se constituye como la única vía para vincular al deudor al proceso, pues en virtud de una posición garantista del derecho de contradicción, figuras como el emplazamiento y el curador ad litem no proceden.

Efectuado lo anterior, puede ocurrir una de la siguientes hipótesis: i) el deudor paga, caso en el cual el proceso termina; ii) el deudor notificado no comparece, conducta que da lugar a que se dicte sentencia condenatoria al pago del monto reclamado, de los intereses causados hasta el momento de la presentación de la demanda y de aquellos que se generen hasta la cancelación de lo debido, sentencia que constituye cosa juzgada y no admite recurso alguno; por último, iii) si el deudor justifica su renuencia al pago aportando las pruebas correspondientes, el litigio se resolverá por los trámites del proceso verbal sumario. La misma consecuencia se producirá respecto de la parte objetada cuando haya oposición parcial. De este modo, el juez dictará el auto correspondiente, citando a las partes a la audiencia del artículo 392, previo traslado por cinco días al demandante para que pida pruebas adicionales.

Para concluir, siempre que se encuentre que el deudor se opuso infundadamente y que, además, resulte condenado en el proceso, será sancionado con una multa equivalente al ro\% del monto pretendido. La misma sanción se impondrá al demandante cuando el deudor resulte absuelto.

\section{Efectos de la oposición en el Código General del Proceso}

El Código General del Proceso atribuye a la oposición del demandado dos efectos. El primero, de carácter procesal, consiste en impedir que se siga adelante con la ejecución de la obligación dineraria, para resolver el asunto por el trámite del proceso verbal sumario. El segundo, por su parte, tiene un tinte sancionatorio que se materializa en la imposición de una multa. A propósito de estas consecuencias, la normatividad cualifica la oposición, imponiéndole al operador jurídico -y al intérprete en general- la carga de determinar bajo qué circunstancias la oposición del demandado surte los efectos que la norma le asigna. 
El artículo 42 I c.g.p. dispone que si la demanda cumple los requisitos exigidos para su admisión, se requerirá al deudor para que en un término de ro días opte por una de las siguientes conductas: i) pagar, ii) guardar silencio o iii) exponer de manera escrita los argumentos por los cuales se opone total o parcialmente a la petición monitoria, para lo cual deberá aportar las pruebas que sustentan su oposición.

Ahora bien, si la oposición es parcial, ya sea porque i) se paga una parte de la deuda reclamada y se opone a la parte restante, o ii) se opone a una parte de la cantidad pretendida y guarda silencio respecto de la otra ${ }^{32}$, el demandante podrá pedir que se prosiga con la ejecución y se dicte sentencia en lo que atañe a la parte no objetada, tal como lo prevén los incisos tercero y cuarto del artículo en cuestión.

La oposición debe ser estudiada en dos momentos procesales. El primero, cuando el demandado contesta la demanda exponiendo los motivos por los cuales cree no deber en todo o en parte. Aunque la norma no lo dice, en este primer momento la oposición debe ser razonada. El segundo, al determinar la imposición de la multa. Para estos efectos, según el Código General del Proceso, la oposición debe ser infundada. En ninguno de los dos casos es claro el alcance de la cualificación, de allí la importancia de definir su contenido.

\section{A. El efecto de impedir la ejecución}

El artículo 42 I c.g.p. preceptúa que si el demandado expone las razones por las que considera no deber en todo o en parte, deberá aportar pruebas suficientes para tal fin, y el asunto será resuelto por el trámite del proceso verbal sumario. Para llevar a cabo lo anterior, el juez deberá citar a la audiencia de que trata el artículo 392 c.g.p. ${ }^{33}$, previo traslado a la parte demandante para que solicite pruebas adicionales, de manera que le sea posible controvertir la oposición expuesta.

32 Canosa Suárez, U., Ley I564 de 2012 con Decreto 1736 de 2012 y notas de constitucionalidad, Bogotá, Instituto Colombiano de Derecho Procesal, 20 I 2, 372.

33 Art. 392 c.g.p.: "En firme el auto admisorio de la demanda y vencido el término de traslado de la demanda, el juez en una sola audiencia practicará las actividades previstas en los artículos 372 y 373 de este código, en lo pertinente. En el mismo auto en el que el juez cite a la audiencia decretará las pruebas pedidas por las partes y las que de oficio considere.

"No podrán decretarse más de dos testimonios por cada hecho, ni las partes podrán formular más de diez (Io) preguntas a su contraparte en los interrogatorios.

"Para la exhibición de los documentos que se solicite [sic] el juez librará oficio ordenando que le sean enviados en copia. Para establecer los hechos que puedan ser objeto de inspección judicial que deba realizarse fuera del juzgado, las partes deberán presentar dictamen pericial.

"En este proceso son inadmisibles la reforma de la demanda, la acumulación de procesos, los incidentes, el trámite de terminación del amparo de pobreza y la suspensión de proceso por causa diferente al común acuerdo. El amparo de pobreza y la recusación solo podrán proponerse antes de que venza el término para contestar la demanda". 
De este modo, los fundamentos expuestos por el deudor y el acreedor permanecerán inmodificables ${ }^{34}$, es decir, el juez está sujeto, de acuerdo con el artículo $28 \mathrm{I}^{[35]}$ c.g.p., al principio de congruencia.

\section{B. Multa}

La multa es una consecuencia procesal que tiene como fin sancionar a las partes que no obren con lealtad procesal, buena fe y seriedad en sus argumentos ${ }^{36}$. Si hacemos un símil con la sanción prevista en el artículo 206 c.g.p. ${ }^{37}$, referente al juramento estimatorio, se advierte que su finalidad es desincentivar conductas temerarias y contrarias a la buena fe procesal $3^{8}$. En consideración a ello, la Corte Constitucional, en sentencia C-279 de $2013^{[39]}$, concluyó que la sanción no puede ser impuesta únicamente en consideración al resultado del proceso, pues este no necesariamente obedece a un actuar negligente o temerario. Así, la imposición de la multa en el juramento estimatorio solo procede cuando la causa de la misma sea imputable a hechos o motivos provenientes de la voluntad de la parte, es decir, a su falta de diligencia.

En este orden de ideas, si bien el legislador tiene la facultad de imponer una multa a la parte vencida en el proceso monitorio, el hecho de que la norma esté redactada de manera genérica, es decir, sin hacer ninguna distinción respecto de las causas por las cuales se produjo la absolución o la condena, no autoriza su imposición únicamente en razón del resultado.

\section{Exigencias de la oposición en otros países}

A efectos de tomar elementos que contribuyan a determinar el contenido y alcance de la oposición, se hará referencia a la regulación de Uruguay, España y Costa Rica, por ser los países que con mayor detalle se ocupan de la oposición.

34 Canosa, ob. cit., 56-57.

35 Art. 28 I c.g.p.: "Congruencias. La sentencia deberá estar en consonancia con los hechos y las pretensiones aducidos en la demanda y en las demás oportunidades que este código contempla y con las excepciones que aparezcan probadas y hubieren sido alegadas si así lo exige la ley".

36 Colmenares Uribe, C., El procedimiento monitorio en América Latina: pasado, presente y futuro, Bogotá, Temis, 2013, I $52-153$.

37 Art. 206 c.g.p.: "Si la cantidad estimada excediere en el cincuenta por ciento (50\%) a la que resulte probada, se condenará a quien hizo el juramento estimatorio a pagar al Consejo Superior de la Judicatura, Dirección Ejecutiva de Administración Judicial, o quien haga sus veces, una suma equivalente al diez por ciento (го\%) de la diferencia entre la cantidad estimada y la probada...".

38 Colombia, Corte Constitucional. Sentencia C- 157 del 2 I de marzo de 2013 , M.P.: Mauricio González Cuervo, exp. D-9263.

39 Colombia, Corte Constitucional. Sentencia C-279 del i 5 de mayo de 2013, M.P.: Jorge Ignacio Pretelt Chaljub, exp. D-9324. 


\section{A. Uruguay}

En primer lugar, es necesario hacer una salvedad, y es que el Código General del Proceso de la República Oriental del Uruguay consagra una categoría general denominada 'proceso de estructura monitoria', la cual engloba varios tipos de procesos, razón por la cual la comparación que a continuación se realiza es limitada, en la medida en que la naturaleza jurídica de esta figura en Uruguay es diferente a la consagrada en Colombia.

El proceso monitorio uruguayo es quizá uno de los más garantes respecto del derecho de defensa, lo cual se refleja en la posibilidad que le da al demandado de presentar "cualquier excepción que tuviere contra la demanda", dentro de un plazo de ro días, tal como se desprende de la lectura del artículo 355 c.g.p.. Así pues, la principal diferencia con respecto al proceso monitorio en Colombia consiste en la aparente privación que existe en este último respecto de la posibilidad de alegar excepciones previas.

\section{B. España}

El artículo 8I 5 de la Ley de Enjuiciamiento Civil, en relación con la oposición, le permite al demandado que "... alegue sucintamente, en escrito de oposición, las razones por las que, a su entender, no debe, en todo o en parte, la cantidad reclamada..." (resaltado fuera de texto).

Aunque existe similitud con lo previsto en el Código General del Proceso colombiano, las expresiones "sucintamente" y "a su entender" le imprimen flexibilidad al contenido de la oposición. Además, la ley no exige al demando que aporte documentos que soporten su oposición, a diferencia del demandante, a quien sí se le exige que aporte documentos.

\section{Costa Rica}

La Ley de Cobro Judicial de Costa Rica (Ley 8624 de 2008) podría ser catalogada como una de las más completas en cuanto a la descripción de los requisitos de la oposición. En primer lugar, el numeral 3 del artículo $5{ }^{\circ}$ de la mencionada ley hace referencia a las posibles conductas que puede adoptar el demandado en el ejercicio de la oposición.

El numeral siguiente dispone que "solo se admitirá la oposición por el fondo que se funde en falsedad del documento, falta de exigibilidad de la obligación, pago o prescripción, sin perjuicio de las excepciones procesales que establezca la ley". Así pues, se puede determinar que la oposición es fundada cuando:

- Se fundamenta en la falsedad del documento.

- La obligación no es exigible.

- Se alega el pago o prescripción. 
- Se interponen las excepciones que establezca la ley.

En los tres primeros casos, la oposición fundada implica necesariamente atacar la obligación, mientras que el cuarto comprende tanto las excepciones previas como las de mérito.

\section{Conclusiones generales respecto al contenido de la oposición en otros países}

La legislación uruguaya confiere al demandado la posibilidad de defenderse por medio de "cualquier excepción que tuviere contra la demanda". A simple vista, el tratamiento que da la legislación colombiana a la oposición es menos garante. Sin embargo, hay que tener en cuenta la salvedad hecha con relación a la estructura monitoria de los procesos en Uruguay, que justifica que las posibilidades de defensa del demandado sean más amplias.

En España, siendo un proceso documental, las exigencias de la oposición son menos rigurosas que las previstas en el Código General del Proceso. En efecto, el demandado puede oponerse exponiendo de forma sucinta las razones por las que considera no deber, sin que sea necesario que aporte prueba de ello. En contraste, la legislación colombiana, donde el proceso también es documental, con la salvedad ya anotada ${ }^{40}$, sí le exige al demandado que aporte pruebas con la oposición. Sin embargo, como se explica adelante, esta exigencia debe ser morigerada.

Por último, en Costa Rica la ley detalla el contenido de la oposición, lo cual da certeza al demandado sobre sus posibilidades de defensa en el proceso monitorio, y, a la vez, orienta al juez a la hora de determinar cuándo hay o no oposición.

\section{Contenido y alcance de las exigencias de la oposición en otras figuras del Código General del Proceso}

Con el objeto de obtener elementos que contribuyan a definir el contenido de la oposición en el proceso monitorio, se identificarán los elementos característicos de la oposición en otras figuras procesales, específicamente en i) el juramento estimatorio, ii) la oposición en la diligencia de entrega y iii) la oposición a la exhibición de documentos.

40 El inciso 2 del numeral 6 del artículo 4I9 c.g.p. señala: "El demandante deberá aportar con la demanda los documentos de la obligación contractual adeudada que se encuentren en su poder. Cuando no los tenga, deberá señalar dónde están o manifestar bajo juramente que se entiende prestado con la presentación de la demanda, que no existen soportes documentales" (resaltado nuestro). 


\section{A. Juramento estimatorio}

La oposición que se hace en este caso es respecto a la estimación económica presentada por la parte demandante en el juramento estimatorio, no con relación a las pretensiones de la demanda, como en el caso del proceso monitorio.

El Código, en su artículo 206, consagra que "quien pretenda el reconocimiento de una indemnización, compensación o el pago de frutos o mejoras, deberá estimarlo razonadamente bajo juramento en la demanda o petición correspondiente, discriminando cada uno de sus conceptos...". En efecto, se le impone al demandante la carga de discriminar cada uno de los rubros que componen el monto total. Dicha discriminación es de vital importancia para la oposición, en la medida en que le da al juez los parámetros necesarios para determinar si la objeción presentada es procedente o no, debido a que el objetante tendrá que hacer referencia de manera razonada a las inexactitudes de cada concepto.

Esta exigencia, si la traemos al proceso monitorio, le impone al demandado una carga de claridad en su oposición.

\section{B. Oposición a la entrega de bienes}

En la diligencia de entrega de bienes, regulada en el artículo 309 c.g.p., puede haber oposición de terceros, con base en hechos constitutivos de posesión. El tercero debe presentar prueba para que prospere la oposición, así como sucede en el proceso monitorio.

En efecto, el primer aspecto característico de esta oposición es que está limitada a la posesión, por lo que el tercero no puede alegar hechos diferentes. El segundo consiste en la exigencia de pruebas como condición de procedencia de la oposición.

La comparación con esta figura, en principio, lleva a concluir que la voluntad del legislador es restringir la oposición. Sin embargo, como se explica más adelante, el asunto no puede ser analizado con ligereza, en la medida en que, en el proceso monitorio, una interpretación restrictiva puede comprometer el derecho de defensa del demandado.

\section{Oposición en el proceso de deslinde y amojonamiento}

En el proceso de deslinde y amojonamiento se admite la oposición de terceros y de parte. De acuerdo con el artículo 403 c.g.p., la oposición de terceros se resuelve según lo regulado para la diligencia de entrega de bienes. Para la oposición de alguna de las partes a los límites trazados, el artículo 404 c.g.p. prevé que el opositor debe presentar una demanda, a la cual, previo traslado a la contraparte, se le da el trámite del proceso verbal. 
Este tratamiento de esta oposición denota la relevancia que les da el legislador a aquellas oposiciones de cuya valoración depende el resultado del proceso.

\section{Oposición a la exhibición de documentos}

El artículo 267 c.g.p. señala que el obligado a la exhibición puede oponerse a la práctica de la prueba. El juez debe apreciar los motivos de la oposición, que debe ser justificada, so pena de que se tengan "por ciertos los hechos que quien pidió la exhibición se proponía probar, salvo cuando tales hechos no admitan prueba de confesión, caso en el cual la oposición se apreciara como indicio en contra del opositor".

De este modo, el legislador ordena al juez que cuando vaya a decidir el fondo del asunto analice si la oposición fue fundada o no, para efectos de imponer las consecuencias que se acaban de mencionar. A pesar de no definir qué debe entenderse por 'fundado', el legislador impone que el análisis de tal cualificación se haga al final del proceso, lo que quiere decir que la mera oposición frustra de entrada la práctica de la exhibición de documentos. Como se explica más adelante, esto es justamente lo que debería suceder en el proceso monitorio.

\section{E. Conclusión general respecto al contenido de la oposición en otras figuras del Código General del Proceso}

De la anterior revisión se advierte que no existe uniformidad ni en el concepto de oposición, ni en los criterios para determinar su contenido, ni en el trámite para resolverla. Lo que sí es claro es que cada caso involucra distintos intereses, que ameritan un tratamiento diferencial. Es por ello que el primer paso hacia la definición del contenido y alcance de la oposición del demandado en el proceso monitorio consiste en identificar los derechos o principios en juego, para, de esa manera, optar por una interpretación más o menos restrictiva de esta figura, que, en todo caso, deberá ser conforme con la Constitución.

\section{Relevancia del alcance de la oposición: defensa y eficiencia}

El proceso monitorio enfrenta dos principios procesales medulares. Por un lado, la celeridad en la tutela efectiva del crédito, y por otro, el derecho de defensa del deudor, quien ve reducidas sus posibilidades y términos para controvertir los hechos y pretensiones alegados por el demandante. Del alcance que se le dé a la oposición del demandado dependerá en gran medida que se privilegie uno u otro principio.

Será deber del juez, entonces, establecer el alcance de la oposición en los dos momentos de valoración que se desprenden de la estructura del proceso monitorio, los cuales hemos denominado 'valoración preliminar' y 'valoración posterior'. 
Esto tendrá como consecuencia la primacía de uno u otro de los principios enfrentados.

\section{A. Valoración preliminar}

La valoración preliminar tiene lugar una vez presentada la contestación de la demanda en la cual se concreta la oposición del demandado. Aquí se evaluará su razonabilidad para, como consecuencia, dar paso al trámite verbal sumario o dictar sentencia condenatoria. Existen dos criterios para determinarla, los cuales denominaremos 'criterio de la oposición trámite' y 'criterio de la oposición valorada'.

\section{Criterio de la oposición trámite}

Se caracteriza por su naturaleza formal, pues el juez se limita a verificar que se cumpla con la carga de oponerse, sin valorar los motivos que dan lugar a ello, verbigracia, el caso en que el demandado en el término de traslado propone como oposición el desconocimiento de la existencia de la deuda de manera genérica. Conocida esta oposición, el juez deberá dar paso al trámite del proceso verbal sumario sin valoración sobre la necesidad de integrar el contradictorio o no.

Para ello, se requiere tener en cuenta que debe cumplirse con la formulación de la contestación de la demanda, aunque esta sea deficiente. En el caso colombiano, la contestación de la demanda satisface la carga de oponerse ${ }^{4 \mathrm{I}}$.

Consecuencia directa de este criterio es que el juez única y exclusivamente podrá dictar sentencia condenatoria, sin pasar al trámite del proceso verbal sumario, en el evento en que el demandado guarde silencio o se allane a las pretensiones. En el resto de escenarios posibles donde haya contestación, sea deficiente o adecuada, se dará paso automáticamente al trámite del proceso verbal sumario, incluso en aquellos casos donde el motivo de la oposición sea una de las prohibiciones expresas del artículo 42 I c.g.p. ${ }^{42}$.

A la luz del criterio de la oposición trámite existen dos posibles posturas frente al eventual trámite del proceso verbal sumario.

La primera implica que en la fase posterior, ante una deficiente contestación de la demanda, donde, por ejemplo, no se realizó un pronunciamiento expreso sobre los hechos o las pretensiones, o se realizaron afirmaciones o negaciones contrarias a la realidad, el juez deberá dar aplicación al artículo 97 c.g.p., que

4I Canosa Suárez, U., "El proceso monitorio", en Código General del Proceso, Ley I 564 de 2012 con Decreto I 736 de 2012 y notas de constitucionalidad comentado, con articulos explicativos de miembros del ICDP, Bogotá, Instituto Colombiano de Derecho Procesal, 2014, 36 I-379.

42 Art. 42 I c.g.p.: "Trámite [...] Parágrafo. En este proceso no se admitirá intervención de terceros, excepciones previas, reconvención, el emplazamiento del demandado, ni el nombramiento de curador ad litem. Podrán practicarse las medidas cautelares previstas para los demás procesos declarativos...". 
consagra efectos procesales negativos a la contestación hecha de manera deficiente, esto es, se tendrán como ciertos los hechos de la demanda que sean susceptibles de prueba de confesión ${ }^{43}$. De tal suerte que en esta hipótesis se le permitirá al demandado defenderse de las pretensiones del demandante dentro del trámite del proceso verbal sumario, a pesar de haber presentado una deficiente contestación de la demanda, eso sí, asumiendo en su integridad los mencionados efectos negativos que la ley consagra.

Una segunda postura, más laxa con la conducta del demandado, indica que se debe dar el trámite del proceso verbal sumario, omitiendo todo tipo de consecuencias procesales desfavorables a este.

La escogencia del criterio de la oposición trámite claramente da prevalencia al derecho de defensa sobre la célere y efectiva tutela del crédito, que se pretende proteger por medio del proceso monitorio. Esto, en la medida en que se otorga un escenario más amplio, valga decir, una fase verbal sumaria al demandado para hacer valer las razones de su renuencia a pagar, además de permitirle presentarse a un juicio con solo satisfacer la carga de oponerse, valiéndose del acervo probatorio para desvirtuar las afirmaciones del demandante.

\section{El requisito probatorio en la oposición}

En esta etapa del proceso, aunque el artículo 42 I c.g.p. no lo señala expresamente, de su redacción resulta que el demandado debe contestar la demanda de forma razonada, "para lo cual deberá aportar las pruebas en que se sustenta su oposición”. Es necesario determinar cuán riguroso debe ser el eventual opositor a la hora de cumplir el requisito de aportar pruebas en la contestación. Existen dos posiciones sobre este requisito de carácter formal.

La primera posición, que hemos denominado 'criterio de la oposición exegética', indica que sin importar la forma en que se haga la demanda, sea con la simple afirmación o con pruebas que sustenten el crédito, al demandado se le exigirá que aporte los elementos probatorios que demuestren su oposición; de lo contrario, el requisito se tendrá por no satisfecho. La Corte Constitucional en sentencia C-726 de $2014^{[44]}$ aseguró que aunque la exigencia de la prueba podría en principio considerarse desproporcionada, se ajustaba a la Constitución en el entendido de que tras integrar el contradictorio, el régimen probatorio sería el general, es decir, que corresponderá al demandante acreditar la obligación y al demandado su extinción.

La segunda, que llamaremos 'criterio de la oposición proporcional', indica que si el demandante aportó pruebas con su reclamación, el demandado deberá hacer lo propio y aportar material probatorio que lleve al juez a dudar sobre la exis-

44 Sentencia C-726 del 24 de septiembre de 2014. 
tencia del crédito reclamado. Por el contrario, si el demandante inició el proceso monitorio con la simple aseveración de que el demandado le debe, no podría exigírsele a este último que presente una prueba de los hechos que alega como sustento para oponerse, cuando no tenga ninguna prueba en su poder, razón por la cual bastará con la negativa a pagar. Este caso toma especial relevancia en las oposiciones que se sustenten, por ejemplo, en una excepción previa que no requiera práctica de pruebas o una negación indefinida de no conocer al acreedor, lo cual está exento de prueba.

\section{Criterio de la oposición valorada}

El segundo criterio para determinar la razonabilidad de la oposición al momento de hacer la valoración preliminar es el de la oposición valorada, que consiste en la verificación por parte del juez, ya no solo del cumplimiento de unos requisitos de carácter formal, como en el criterio de la oposición trámite, sino, además, de que haya en la oposición motivos suficientes para plantear una controversia sobre la existencia o no del crédito reclamado por el demandante, y que en estas encuentre mérito suficiente para integrar el contradictorio a través del trámite del proceso verbal sumario. De no ser así, la contestación se tendrá por no razonada y se dictará sentencia.

Se constata entonces que este criterio da prevalencia a la celeridad de la tutela del crédito, aunque en algunos casos esa valoración preliminar pueda concretarse en una disminución del derecho de defensa del demandado. Esto, ya que el deudor no tendrá la oportunidad de acceder a un juicio en el cual, mediante un debate más profundo, pueda hacer valer hechos que no hayan sido alegados en la contestación de la demanda pero que resulten probados, ni tampoco valerse de pruebas que haya presentado la contraparte. Esta situación adquiere mayor relevancia al tener en cuenta que el legislador estatuyó que en este proceso no se requiere apoderado judicial.

No obstante, esto se justifica en la naturaleza propia del proceso monitorio, que busca la descongestión judicial, evitar dilaciones injustificadas en el proceso y, en general, el efectivo acceso a la administración de justicia.

\section{B. Valoración posterior}

El segundo momento de valoración tiene lugar únicamente en el caso en que se haya seguido el trámite del proceso verbal sumario, cuando el juez vaya a dictar sentencia. Consiste en determinar lo fundado o infundado de la oposición que hace el demandado, para efectos de decidir sobre la imposición o no de la multa prevista por el Código. De tal suerte que para definir cuándo, cómo y por qué se impondrá la multa, deberá determinarse si la valoración que se hace al momento de imponerla es objetiva o subjetiva. 
La sanción objetiva es aquella que se impone a la parte que pierde el proceso, sin importar qué tan serios hayan sido los argumentos que llevaron al demandante a impetrar su demanda, o al demandado a oponerse a la misma. Es decir, si el demandado pierde será castigado con la multa, pero si el demandante es quien pierde, será entonces el sujeto sobre el cual recaerá la misma45.

La sanción subjetiva, en contraste, es aquella en la que alguna de las partes es destinataria de una sanción de acuerdo con su conducta al interior del proceso. En consecuencia, solo se impondrá un castigo a aquella parte que haya actuado de manera desleal, ya sea al demandante por incoar una acción en contra del demandado sin tener fundamento alguno, contrariando la buena fe procesal, o al demandado porque se opuso sin tener motivos suficientes que demuestren que las razones que esgrime dentro de la contestación de la demanda están respaldadas como para creer razonablemente que la deuda no existía. En conclusión, todo quedará resumido en el obrar temerario de las partes ya sea al demandar o al contestar la demanda.

Establecer, entonces, las posibles interpretaciones del alcance de la sanción, permite dilucidar en cuál de los eventos realmente se está protegiendo la lealtad procesal mediante su imposición, y en cuáles, por el contrario, aunque se pretenda salvaguardar este principio, se contraría el mismo o se afectan otra serie de garantías fundamentales.

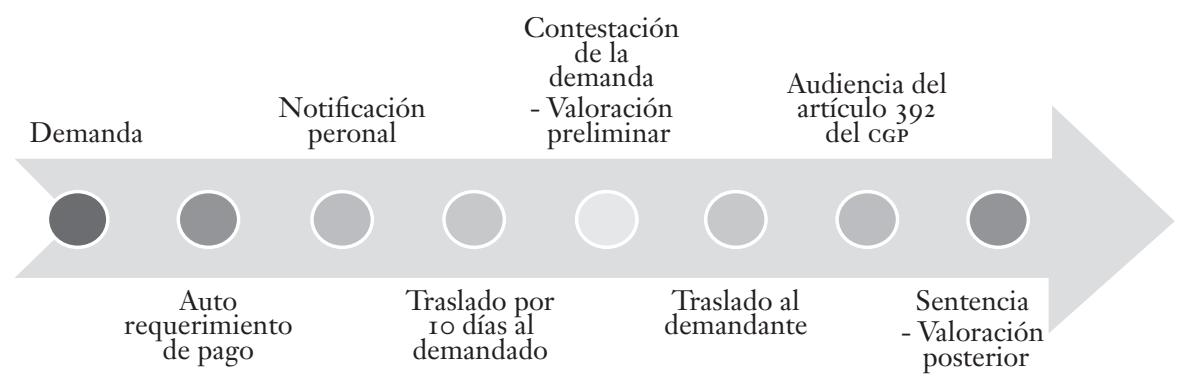

\section{En busca de un criterio de valoración adecuado}

A continuación se expondrán los criterios propuestos para precisar la interpretación adecuada de la cualificación que hace el legislador de la oposición, tanto en la valoración posterior como en la preliminar, conforme a los principios constitucionales que orientan este proceso: el derecho de defensa y la tutela efectiva del crédito.

45 Es importante recordar que en Colombia las sanciones por responsabilidad objetiva son de carácter excepcional. Nuestro sistema jurídico civil tiene como regla general la imputación de responsabilidad a causa de la valoración subjetiva del comportamiento del individuo mediante las categorías de culpa y dolo. Cfr. Colombia, Corte Constitucional. Sentencia C-i 8 i de 2002, M.P.: Marco Gerardo Monroy Cabra, exp. D-3676. 


\section{A. Sobre la valoración preliminar}

Para determinar el criterio más acorde con los principios de eficiencia de la administración de justicia y celeridad de sus actuaciones, sin sacrificar el derecho de defensa del demandado, es necesario hacer un juicio de ponderación que permita valorar con mayor precisión la oposición. Para ello, debemos acudir a los criterios esgrimidos por la jurisprudencia de la Corte Constitucional:

La teoría jurídica alemana, partiendo de la jurisprudencia del Tribunal Constitucional Federal, ha mostrado cómo el concepto de razonabilidad puede ser aplicado satisfactoriamente solo si se concreta en otro más específico, el de proporcionalidad. El concepto de proporcionalidad sirve como punto de apoyo de la ponderación entre principios constitucionales: cuando dos principios entran en colisión, porque la aplicación de uno implica la reducción del campo de aplicación de otro ${ }^{46}$.

De manera que, teniendo en cuenta la importancia de diferenciar los criterios de oposición propuestos, es pertinente preguntarnos respecto del criterio que adoptamos: ¿es razonable privilegiar el derecho de defensa sobre el principio de celeridad que se predica de la tutela efectiva del crédito? Para dar una solución, procedemos a realizar un test de proporcionalidad respecto de estos principios.

La Corte ha establecido tres etapas que desarrollan el test de proporcionalidad. Cada una debe superarse satisfactoriamente para avanzar a la siguiente; estas son:

I. Determinar el fin buscado por el trato desigual.

2. Confrontar los hechos con el texto constitucional para establecer la validez del fin a la luz de los valores, principios y derechos consignados en este.

3. Examinar la razonabilidad del trato diferenciado 47.

Procedemos a desarrollar cada una de las etapas del mismo, formulándolas como preguntas y dándoles respuesta.

\section{I. ¿Cuál sería la finalidad perseguida por el legislador si se diera paso al proceso verbal sumario, independientemente de la defensa que plantee el demandado?}

Debemos traer a colación bajo primicia la interpretación auténtica que llevó a la implementación del proceso monitorio en Colombia, es decir, la inclusión de un instrumento procesal que brindara oportunidad a los acreedores de bajas cuan-

46 Colombia, Corte Constitucional. Sentencia C-022 del 23 de enero de i996, M.P.: Carlos Gaviria Díaz, exp. D-ıoo8.

47 Ibíd. 
tías, para hacer efectivo su derecho de crédito de una manera célere y eficiente ante la ausencia de título ejecutivo. No obstante, ello debe entenderse sin olvidar que está en juego el derecho de defensa del demandado.

Es acertado que se invierta el contradictorio dentro de este tipo de procesos con el fin de evitar dilaciones injustificadas, pero no que el demandado cuente con menos oportunidades procesales para hacer valer sus derechos, de tal manera que pueda encontrarse en una situación de desequilibrio respecto de su contraparte. Así pues, debe llegarse a un punto medio donde se entienda la validez de los principios que aspira proteger el proceso monitorio, bajo la condición de que no se desamparen otros derechos. Entonces, solamente se dictará sentencia en el escenario en que el demandado no se oponga, de manera que cuando lo haga se le brinden otras oportunidades procesales para que haga valer sus derechos, es decir, en el trámite del proceso verbal sumario podrá justificar las razones de su oposición, sin perjuicio de las consecuencias procesales posteriores a que dé lugar su actuación poco diligente o injustificada. Con todo lo anterior evidenciamos que la finalidad perseguida es privilegiar el derecho de defensa del demandado sobre la tutela efectiva del crédito, en el sentido de pasar siempre y en todo caso al trámite del proceso verbal sumario ante cualquier oposición que se formule.

\section{2. ¿Privilegiar el derecho de defensa es un fin válido a la luz de nuestra Constitución?}

En este punto debemos traer a colación la sentencia C-025 de 2009, en la cual la Corte señaló, a propósito del derecho de defensa:

Una de las principales garantías del debido proceso, es precisamente el derecho a la defensa, entendido como la oportunidad reconocida a toda persona, en el ámbito de cualquier proceso o actuación judicial o administrativa, de ser oída, de hacer valer las propias razones y argumentos, de controvertir, contradecir y objetar las pruebas en contra y de solicitar la práctica y evaluación de las que se estiman favorables, así como de ejercitar los recursos que la ley otorga. Su importancia en el contexto de las garantías procesales, radica en que con su ejercicio se busca impedir la arbitrariedad de los agentes estatales y evitar la condena injusta, mediante la búsqueda de la verdad, con la activa participación o representación de quien puede ser afectado por las decisiones que se adopten sobre la base de lo actuado ${ }^{4}$.

48 Colombia. Corte Constitucional. Sentencia C-025 del 27 de enero de 2009, M.P.: Rodrigo Escobar Gil, exp. D-7226. 
De este modo, es necesario concluir que la protección al derecho de defensa no solo es un fin válido a la luz de nuestra Constitución, fundado en el respeto al debido proceso consagrado en su artículo 29, sino que es una garantía transversal, especialmente privilegiada, en el ordenamiento jurídico.

\section{3. ¿Es razonable privilegiar el derecho de defensa, limitando el principio de celeridad que se predica de la tutela efectiva del crédito?}

Analizaremos el último de los puntos haciendo uso del método mayéutico, mediante tres interrogantes:

(a) ¿Al morigerar levemente el principio de celeridad y el derecho a la tutela efectiva del crédito, logramos proteger el derecho de defensa?

Como se dijo al explicar el criterio de la oposición trámite, si le otorgamos oportunidad al demandado de defenderse, dando paso al trámite del proceso verbal sumario, aun en la hipótesis en que haya realizado una contestación deficiente de la demanda, se le está otorgando una prerrogativa procesal para hacer valer sus derechos, alargando un poco el proceso pero garantizando el derecho de defensa de manera equilibrada.

Lo anterior no consiste en premiar su conducta tal vez negligente, sino en nivelar y estabilizar las oportunidades procesales con las que cuentan las partes dentro del proceso. A favor de este argumento cabe decir que el demandado no se libra de las consecuencias de su posible mala conducta, pues si bien no se va a dictar sentencia inmediatamente, sí va a soportar las consecuencias que se derivan del artículo 97 c.g.p. ${ }^{49}$, sin perjuicio de la sanción consagrada en su artículo 42 I en caso de probarse que se opuso de manera infundada.

(b) ¿Es necesario sacrificar el principio de celeridad en la tutela efectiva del crédito para proteger el derecho de defensa? ¿Existen otros medios que resulten menos gravosos en términos de vulneración de principios?

En este punto, la única manera de garantizar el derecho de defensa a favor del demandado es brindándole las oportunidades procesales de las cuales es merecedor en virtud de lo dispuesto en el artículo 29 CP. Esto implica una extensión

49 Art. 97 c.g.p.: "La falta de contestación de la demanda o de pronunciamiento expreso sobre los hechos y pretensiones de ella, o las afirmaciones o negaciones contrarias a la realidad, harán presumir ciertos los hechos susceptibles de confesión contenidos en la demanda, salvo que la ley le $[s i c]$ atribuya otro efecto.

"La falta del juramento estimatorio impedirá que sea considerada la respectiva reclamación del demandado, salvo que concrete la estimación juramentada dentro de los cinco (5) días siguientes a la notificación del requerimiento que para tal efecto le haga el juez". 
del iter procesal para llegar a una situación de certidumbre y verdad jurídica en la que sea posible dictar sentencia.

Contrario sensu, omitir el desarrollo de una fase en la que se presente el contradictorio dentro del proceso, en la cual el demandado pueda hacer uso de las oportunidades procesales correspondientes para ejercer de manera eficiente su derecho de defensa, no resulta viable, puesto que este escenario es el único apto para el pleno desarrollo del derecho en mención.

(c) ¿El grado de sacrificio del principio de celeridad en la tutela efectiva del crédito se justifica respecto del grado de satisfacción que se está proporcionando al proteger el derecho de defensa del demandado que se opone deficientemente?

Finalmente, procedemos a realizar el juicio de proporcionalidad en sentido estricto. Alrededor de este punto deben tenerse en cuenta los pesos y contrapesos que serán puestos en la balanza, de tal forma que estos dos derechos puedan vivir sin conflicto, en alianza y sin vulnerar el núcleo esencial del otro.

Siendo así, debe decirse que proteger el derecho de defensa, garantizando la posibilidad del demandado de defenderse mediante el trámite del proceso verbal sumario, no constituye riesgo o transgresión alguna al principio de celeridad en la tutela efectiva del crédito, pues no es corolario de esta garantía que el juez no pueda fallar dentro del término previsto en el Código, ni que se desprotejan las acreencias por vía judicial. Antes bien, se logra que el juez realice un trabajo más a fondo respecto de la situación fáctica que se discute en el proceso.

En contraste, la tutela desmedida del crédito y la celeridad absoluta sí constituyen desproporción para las partes, toda vez que se puede llegar a prescindir de realidades de fondo y de forma, simplemente por dar paso a una tutela célere del crédito, presumiendo la culpabilidad del demandado.

Aunado a ello, se le estaría dando celeridad a un proceso donde el juez puede no contar con las herramientas suficientes para poder fallar. No significa entonces que se deba prescindir del proceso monitorio, más bien se va a seguir protegiendo a los pequeños acreedores sin título ejecutivo, sin caer en extremos y desequilibrios, es decir, con el cuidado de arriesgar lo necesario, dándole prevalencia, en este caso específico, al derecho de defensa.

Así las cosas, el test arroja que es proporcional proteger el derecho de defensa sobre el principio de celeridad. De esta manera, consideramos que en el momento de la valoración preliminar se debe optar por el criterio de la oposición trámite, valga decir, es necesario que el juez dé paso al proceso verbal sumario en un primer momento, ante toda oposición del demandado.

Habiendo tomado el criterio de la oposición trámite, cabe aclarar que este se debe ver complementado con el criterio de la oposición proporcional. Si bien la Corte Constitucional se pronunció sobre la exequibilidad de la exigencia proba- 
toria ${ }^{5}$, consideramos que debe hacerse la salvedad de que esta no aplica en los excepcionales casos de hechos exentos de prueba, tales como las afirmaciones o negaciones indefinidas, o las excepciones previas que no requieren prueba. Optar por un criterio distinto sería inequitativo, puesto que implicaría cargas más exigentes en cabeza del deudor que en la del acreedor, incluso violando la buena fe que se debe presumir de la conducta de las partes y el principio de igualdad de estas dentro del proceso.

Sin embargo, consideramos que esta postura se atempera en la medida en que la oposición deficiente no implica que no se vaya a pasar a la segunda fase del proceso (audiencia del proceso verbal sumario), sino que tendrá los efectos negativos consagrados en el artículo 97 c.g.p., ya mencionados.

La aplicación del criterio de la oposición trámite con los matices ya acotados, es por demás fundamental, puesto que al ser notable la ausencia de conocimientos técnicos en el momento inicial del proceso monitorio si el demandado se opone, se debe dar paso al trámite del proceso verbal sumario para que allí, bajo la dirección del juez, en uso de las amplias facultades que le otorga el Código, se logre la subsanación de las falencias técnicas para poder llevar a cabo un proceso donde prevalezcan los principios de la verdad y la justicia.

\section{B. Sobre la valoración posterior}

En la valoración posterior, es decir, la que tiene lugar al momento de la imposición de la multa, debe tomarse un criterio de calificación subjetiva, toda vez que esta se desarrolla de la mano del artículo 42 I c.g.p., el cual atempera el elemento objetivo respecto de la parte demandada cuando, además de poner como requisito para la imposición de la multa el que sea condenado, exige también que la oposición sea infundada. Este último elemento debe ser entendido como la ausencia de temeridad y malicia en el actuar procesal de las partes.

Se debe recordar que los poderes correccionales del juez y las multas dentro del proceso judicial hacen parte del derecho administrativo penal disciplinario, que debe ceñirse a los principios del derecho punitivo, teniendo como marco especial el artículo ${ }_{29} \mathrm{CP}^{5 \mathrm{I}}$.

En este caso, como se expuso, la norma no es del todo clara, permitiendo varias interpretaciones sobre la forma de imposición de la multa. Por tal motivo, debe recordarse que las sanciones por responsabilidad objetiva son de carácter excepcional, puesto que pueden llegar a contrariar los principios de dignidad

50 Sentencia C-726 de 2014 del 24 de septiembre de 2014.

5 I Colombia, Instituto de Estudios del Ministerio Público, Lecciones de Derecho Disciplinario, v. 2, Bogotá, Procuraduría General de la Nación, $2007,308$. 
humana y de culpabilidad (arts. I. ${ }^{\circ}$ y $\left.29 \mathrm{CP}\right)^{5^{2}}$, de manera que se requiere que su interpretación sea restrictiva 53 .

En palabras de la Corte:

[E]l cargo del actor carece de fundamento, pues el artículo acusado debe ser interpretado de conformidad con la Constitución, y es obvio que en un Estado social de derecho, fundado en la dignidad humana (CP art. I), no es admisible la responsabilidad objetiva en el campo sancionatorio. Además, el artículo 29 establece con claridad un derecho sancionador de acto y basado en la culpabilidad de la persona, pues dice que nadie puede ser juzgado "sino conforme a leyes preexistentes al acto que se le imputa" y que toda persona se presume inocente "mientras no se le haya declarado judicialmente culpable" 54 (resaltados en texto original).

En razón de lo anterior, se debe preferir el criterio que hace la valoración subjetiva de la conducta procesal de la parte.

No obstante, esta fórmula en la que el juez deberá examinar si existen argumentos de peso suficientes para que el demandado se oponga a la pretensión del proceso monitorio, es decir, que no haya habido temeridad o malicia en el actuar del demandado dentro del proceso, debe hacerse también extensiva al demandante, en el entendido de que no se le puede imponer la multa tan solo porque el demandado resulte absuelto. Se debe hacer el mismo análisis que se predica del demandado para efectos de la imposición de una sanción, atendiendo a que esta castiga el actuar desleal de las partes, por lo cual se requiere analizar si el demandante tenía elementos de juicio suficientes para iniciar el proceso con el convencimiento pleno de tener la razón, es decir, del demandante también se debe predicar una conducta leal.

52 Colombia, Corte Constitucional. Sentencia C-6i 6 del 6 de agosto de 2002, M.P.: Manuel José Cepeda Espinosa, exp. D-3860.

53 "En este orden de ideas, como lo ha sostenido reiteradamente esta Corporación, las normas que introducen excepciones a los derechos fundamentales son de interpretación restrictiva, pues la propia Constitución Política les reconoce un orden preferente al darles primacía sobre el resto de disposiciones que conforman el ordenamiento jurídico (artículos $5 \cdot^{\circ}$ y $93 \mathrm{CP}$ ), a la vez que su protección, vigencia y salvaguarda constituye un fin esencial del Estado": Colombia, Corte Constitucional. Sentencia C-095 del i i de febrero de 2003 , M.P.: Rodrigo Escobar Gil, exp. D-4I72.

54 Colombia, Corte Constitucional. Sentencia C-597 del 6 de noviembre de i996, M.P.: Alejandro Martínez Caballero, exp. D-I 229. 


\section{De las excepciones como consecuencia de un criterio apropiado para la oposición}

La oposición, entendida como el mecanismo inicial y principal que tiene el demandado para resistir las pretensiones del demandante, puede manifestarse en la formulación tanto de excepciones previas como de mérito. $\mathrm{Al}$ respecto, Devis Echandía señala: "en sentido propio, la excepción es una especial manera de ejercitar el derecho de contradicción o de defensa en general que le corresponde a todo demandado, y que consiste en oponerse a la demanda para atacar las razones de la pretensión del demandante, mediante razones propias de hechos, que persigan destruirla o modificarla o aplazar sus efectos" 55 .

En este punto procederemos a definir qué excepciones son admisibles de acuerdo a los criterios adoptados anteriormente, en concordancia con las disposiciones procesales del ordenamiento jurídico colombiano.

\section{A. Excepciones de mérito}

De la lectura del artículo 42 I c.g.p. se constata que no está proscrita la posibilidad de proponer excepciones de fondo para resistirse a las pretensiones de la demanda. Dicha lectura resulta lógica al analizar tanto el objetivo de la oposición como la naturaleza misma de las excepciones de mérito, puesto que es el mecanismo consagrado por la ley para que el demandado introduzca al proceso hechos nuevos. Estos tienen como propósito atacar directamente la pretensión del demandante, de tal forma que de ser verificados se dicte sentencia favorable al demandado ${ }^{5}$.

Al consultar el objetivo de la oposición en los términos del mismo artículo, que la consagra como la oportunidad que tiene el demandado para manifestar “... con explicación de las razones por las que considera no deber en todo o en parte..."57, queda claro que las excepciones de mérito reflejan el espíritu mismo de la oposición: atacar las razones que esgrime el demandante para afirmar tener un crédito a su favor.

\section{B. Excepciones previas}

El panorama, con respecto a la interposición de excepciones previas dentro del proceso monitorio, no resulta tan evidente como lo es para las excepciones de

55 Devis Echandía, H., Nociones generales de Derecho Procesal Civil, Madrid, Aguilar, i966, 230, citado por Mojica, F., "Las excepciones de mérito en el proceso ejecutivo promovido por acción cambiaria", Via Inveniendi et Iudicandi, [en línea], n. ${ }^{\circ}$ 6, junio, 2008, disponible en: http:// basesbiblioteca.uexternado.edu.co: 2 I 34/\#/vid/42 I 85878

56 Cfr. Mojica, F., Las excepciones de mérito en el proceso ejecutivo promovido por acción cambiaria, cit.

57 Ley I 564 de 2012 . Artículo 42 I. 
mérito. Esta dificultad responde, entre otros, al concepto mismo de excepción previa, entendida como la que "no se dirige contra las pretensiones del demandante sino que tiene por objeto mejorar el procedimiento, mejora que en algunos casos implica que se suspende la actuación" ${ }^{5} 8$. La excepción previa así comprendida no cabría dentro del concepto de oposición formulado en el artículo 42 I c.g.p., toda vez que allí se regula expresamente como la oportunidad de exponer las razones por las que considera el demandado no deber en todo o en parte, es decir, motivos de fondo que ataquen la pretensión de pago del demandante. A esto se suma la prohibición del parágrafo del artículo sub examine, que impide la formulación de las excepciones previas en el proceso monitorio.

Lo anterior resulta en una flagrante violación del derecho de defensa, que les debe ser garantizado a las partes dentro de las actuaciones judiciales, pues en principio no se entenderían como oposición aquellos hechos que si bien no atacan de fondo la pretensión del demandante, apuntan a poner en conocimiento del juez ciertos eventos que en la generalidad de los procesos no permitirían continuar con el trámite. Esto, ya sea porque le ponen fin, como en el caso de la excepción de cosa juzgada ${ }^{59}$, o porque constituyen violaciones que más adelante pueden acarrear una nulidad de lo actuado, como pasaría con la no integración del litisconsorcio necesario, que viola el derecho de defensa de aquellos, que aun debiendo ser partes en el proceso no tienen conocimiento del mismo.

Según López Blanco ${ }^{60}$, las excepciones previas son una figura procesal que tiene larga tradición en el derecho colombiano: desde el Código Judicial de I93 I, en el que fueron llamadas 'excepciones dilatorias', pasando por la regulación del Código de Procedimiento Civil, donde finalmente tomarían el nombre de 'excepciones previas', ya que la anterior expresión le daba un significado totalmente distinto al que en realidad tenía, hasta hoy, cuando el Código General del Proceso las consagra taxativamente en su artículo ıoo.

Aquellos hechos constitutivos de excepciones previas no siempre se han podido alegar por el trámite procesal de las excepciones previas como tal, ya que en ocasiones, en búsqueda de celeridad, se ha prohibido este camino procesal, pero se ha permitido alegar dichos hechos por medio del recurso de reposición contra el auto admisorio de la demanda, o el mandamiento de pago, en el caso del proceso ejecutivo. En estas situaciones, si bien se pretende darle un trámite rápido a la ejecución de aquellas deudas donde ya hay un título ejecutivo, se permite alegar todo aquello que constituye excepción previa, para blindar el proceso

$5^{8}$ López Blanco, H., Instituciones de derecho procesal civil colombiano, 2. ${ }^{a}$ ed., Bogotá, Temis, I979, 334 .

59 Que no le permite al juez seguir conociendo respecto de la controversia porque ya existe una decisión judicial al respecto.

6o López Blanco, ob. cit., 334. 
de futuras nulidades, lo cual se torna en una garantía para las partes y para la administración de justicia.

En este orden de ideas, podemos afirmar con certeza que el legislador siempre fue cuidadoso a la hora de imprimir celeridad a los procesos, sin sacrificar las garantías que la Constitución consagra para las partes (derecho de defensa en el caso específico). Dicha precaución se vio reflejada en la implantación de dos caminos claros para poner en conocimiento del juez hechos constitutivos de excepciones previas: i) mediante un escrito separado de la contestación de la demanda donde se planteen los hechos que la constituyen, y ii) por medio del recurso de reposición contra el auto admisorio de la demanda o el mandamiento de pago.

El problema se encuentra cuando al analizar las prohibiciones expresas que hizo el legislador en el proceso monitorio, por medio del parágrafo del artículo 42 I c.g.p., nos encontramos con que "en este proceso no se admitirá [...] excepciones previas..."6I. Asimismo, en el segundo inciso del mismo precepto normativo se establece que “... el auto que contiene el requerimiento de pago no admite recursos..." ${ }_{2}$, razón por la cual en el trámite del proceso monitorio nos quedamos sin los dos caminos procesales que tradicionalmente se han contemplado para interponer excepciones previas.

Es por lo anterior que en el proceso monitorio resulta indispensable que por medio de la oposición del demandado se pongan en conocimiento del juez los hechos que constituyen excepciones previas, teniendo así una tercera vía procesal para este fin. Sumado a ello, se observa que en la Ley de Enjuiciamiento Civil española, en la Ley de Cobro Judicial costarricense y en el Código General del Proceso uruguayo, a los que nos referimos en el cuarto acápite, hay lugar a la interposición de excepciones previas como medio de defensa al interior del proceso monitorio.

Aún más relevante resulta la consagración de este camino procesal al analizar aquellos hechos constitutivos de excepciones previas que, por su naturaleza, son de imposible conocimiento del juez, si una de las partes no se lo pone de presente; por tanto, no podría reconocerlos de oficio en el eventual trámite de la audiencia del proceso verbal sumario, tal como lo es la excepción de pacto arbitral o la de integración del litisconsorcio.

Si bien la Corte Constitucional, en Sentencia C-726 de $2014^{[63]}$, estudió la constitucionalidad de la regulación legal del proceso monitorio en Colombia y declaró la exequibilidad de las prohibiciones del parágrafo del artículo $42 \mathrm{I}$ c.g.p., no hizo un análisis exhaustivo sobre los posibles escenarios en los cuales la imposibilidad de alegar excepciones previas trae como consecuencia la vulneración del debido proceso. En concordancia con lo expuesto, debe entenderse que

6I Ley I 564 de 2012.

62 López Blanco, ob. cit., 334.

63 Sentencia C-726 del 24 de septiembre de 2014 . 
la declaratoria de constitucionalidad mencionada no se refiere a la prohibición de alegar hechos constitutivos de excepciones previas, sino al camino procesal propio de las mismas.

Así las cosas, se concluye que el proceso monitorio es constitucional cuando garantiza el derecho de defensa, permitiendo que el juez conozca los hechos constitutivos de excepciones previas recorriendo este tercer camino procesal: la oposición.

La oposición como medio idóneo para proponer excepciones previas resulta relevante en el evento en que el operador judicial opte por el criterio de la oposición trámite, donde la alegación de estos hechos funge como oposición. Sin embargo, es de mayor trascendencia si se opta por el criterio de la oposición valorada, puesto que, de ser así, el juez hace un verdadero examen de fondo de la oposición en la fase preliminar de valoración, y de no encontrar mérito suficiente en ella, no da paso al trámite de la audiencia del proceso verbal sumario, sino que procede a dictar sentencia, violando los derechos que se protegen a través de este mecanismo, como en el caso de la excepción previa por falta de competencia, donde se violaría el principio del juez natural.

De manera que no habría oportunidad alguna para el demandado de poner en conocimiento del juez los hechos que constituyen excepción previa, violando así el derecho fundamental de defensa que tiene el demandado.

En la actual regulación del proceso monitorio, la oposición ha sido restringida a los hechos que desvirtúan la existencia de la obligación. Sin embargo, es forzoso señalar que la oposición es el único camino procesal sensato que tiene el demandado para proponer los hechos constitutivos de excepciones previas, pues aunque no ataquen las pretensiones de la demanda, sí es un derecho del demandado ponerlas en conocimiento del juez.

\section{Conclusiones}

I. La figura del proceso monitorio es una novedad del Código General del Proceso que pretende hacer efectiva la tutela del crédito por medio de una mayor celeridad de las actuaciones judiciales. Para ello se contempla una inversión del contradictorio que puede entrar en conflicto con el derecho de defensa.

2. Existen dos momentos de valoración por parte del juez de la oposición que presenta el demandado. El primero, la valoración preliminar, busca establecer si la oposición es razonable y, en consecuencia, determinar si debe dársele el trámite del proceso verbal sumario o debe dictarse sentencia condenatoria. En un segundo momento, valoración posterior, el juez deberá establecer la fundabilidad de la oposición y, con base en ello, imponer la sanción que contempla la figura.

3. La valoración preliminar debe enmarcarse en el ámbito del criterio de la oposición trámite, lo cual privilegia el derecho de defensa, evitando así atropellos a este en búsqueda de una célere tutela del crédito. 
4. El paso al trámite del proceso verbal sumario, como consecuencia de la valoración preliminar, es idóneo para permitir al demandado ejercer de manera óptima el derecho de defensa.

5. Para poner en conocimiento del juez aquellos hechos que son constitutivos de excepción previa, se deberá entender que la oposición puede estar sustentada en ellos, ya que el legislador ha proscrito los mecanismos que tradicionalmente se han consagrado para ese propósito en otros procesos. Una conclusión en otro sentido vulnera el derecho de defensa del demandado.

6. La valoración posterior debe desarrollarse con base en el criterio subjetivo para que de esta forma se imponga una sanción a la parte que realmente ha actuado de manera desleal, puesto que el simple hecho de perder el proceso no implica que la parte vencida haya actuado de forma temeraria. 